\title{
Modification of reactive oxygen species scavenging capacity of chloroplasts through plastid transformation
}

\author{
Miranda Poage • Bénédicte Le Martret • \\ Marcel A. K. Jansen • Gregory D. Nugent • \\ Philip J. Dix
}

Received: 2 July 2010/ Accepted: 2 May 2011/Published online: 15 May 2011

(C) Springer Science+Business Media B.V. 2011

\begin{abstract}
Reactive oxygen species (ROS), including superoxide anions, hydrogen peroxide and hydroxyl radicals are generated through normal biochemical processes, but their production is increased by abiotic stresses. The prospects for enhancing ROS scavenging, and hence stress tolerance, by direct gene expression in a vulnerable cell compartment, the chloroplast, have been explored in tobacco. Several plastid transformants were generated which contained either a Nicotiana mitochondrial superoxide dismutase (MnSOD) or an Escherichia coli glutathione reductase (gor) gene. MnSOD lines had a three-fold increase in MnSOD activity, but interestingly a five to nine-fold increase in total chloroplast SOD activity. Gor transgenic lines had up to 6 times higher GR activity and up to 8 times total glutathione levels compared to wild type tobacco. Photosynthetic capacity of transplastomic plants, as measured by chlorophyll content and variable fluorescence of PSII was equivalent to non-transformed plants.
\end{abstract}

\section{Present Address:}

M. Poage

Department of Biology, Midland College, Midland, TX 79705, USA

M. A. K. Jansen

ZEPS Plant Ecophysiology Group, School of Biological, Earth and Environmental Sciences, University College Cork, Cork, Ireland

Present Address:

G. D. Nugent

School of Applied Sciences, Biotechnology and Environmental

Biology, RMIT University, Melbourne, VIC 3083, Australia

B. Le Martret · P. J. Dix ( $\square)$

Biology Department, National University of Ireland Maynooth, Maynooth, Co. Kildare, Ireland

e-mail: phil.dix@nuim.ie
The response of these transplastomic lines to several applied stresses was examined. In a number of cases improved stress tolerance was observed. Examples include enhanced methyl viologen (Paraquat)-induced oxidative stress tolerance in Mn-superoxidase dismutase overexpressing plants, improved heavy metal tolerance in glutathione reductase expressing lines, and improved tolerance to UV-B radiation in both sets of plants.

Keywords Chloroplast transformation - Superoxide dismutase $\cdot$ Glutathione reductase $\cdot$ Abiotic stress

\section{Introduction}

Reactive oxygen species (ROS) are partially reduced, forms of oxygen, routinely produced during normal metabolic processes such as photosynthesis and cellular respiration (Mittler 2002). Light-dependent electron transport processes render the chloroplast a particularly prolific source of ROS, generating superoxide anions $\left(\mathrm{O}_{2}{ }^{--}\right)$and hydrogen peroxide $\left(\mathrm{H}_{2} \mathrm{O}_{2}\right)$, which, through transition metal catalysis, can undergo Fenton reactions to liberate the particularly reactive, and highly destructive, hydroxyl radical $\left(\mathrm{OH}^{\circ}\right)$ (Lidon and Teixeira 2000). ROS have a high capacity for oxidation of a wide range of cellular components, including lipids, nucleic acids and proteins (Badawi et al. 2004a), disrupting a range of cellular functions and leading to extensive cell damage. During normal metabolism ROS levels are kept in check by a battery of enzymic and nonenzymic anti-oxidants which have evolved for the purpose. The front line enzymes in this process are superoxide dismutases (SODs), which convert $\mathrm{O}_{2}{ }^{--}$into $\mathrm{H}_{2} \mathrm{O}_{2}$. This in turn needs to be removed through the action of catalase (CAT), or through cycles such as the water-water cycle, the 
ascorbate-glutathione cycle, or the glutathione peroxidase cycle (Mittler 2002). These cycles employ additional enzymes including ascorbate peroxidase (APX), monodehydroascorbate reductase (MDAR), dehydroascorbate reductase (DHAR), glutathione reductase (GR) and glutathione peroxidase (GPX). Non-enzymic players include ascorbate (AsA) and glutathione, in reduced (GSH) or oxidised (GSSG) form.

It is well established that a wide range of abiotic stresses, including light, temperature, drought, ionic stresses and UV radiation, disrupt cellular homeostasis leading to substantial increases in ROS levels, such that the scavenging mechanisms may be overwhelmed leading to cell damage (Mittler 2002). Inevitably, therefore, ROS scavenging capacity has been long recognised as a target for genetic engineering (Foyer et al. 1994; Allen 1995; Bhatnagar-Mathur et al. 2008), and over-expression of genes encoding enzymic components of these defences has been explored in a number of studies. The most intensively studied has been the over-expression of SOD. Several cDNAs have been expressed in transgenic plants, and while some gave no apparent improvement in stress tolerance (e.g. Tepperman and Dunsmuir 1990), most did result in enhanced tolerance to one or more of the abiotic stresses examined. Expression of MnSOD (normally located in the mitochondria, but targeted to the chloroplast in most of these studies) resulted in improved frost tolerance in alfalfa (McKersie et al. 1993), cold and oxidative stress tolerance in maize (Van Breusegem et al. 1999), drought (Wang et al 2005) and salt tolerance in rice (Tanaka et al. 1999), and salt tolerance in poplar (Wang et al. 2010). Levels of the Fe or Cu/Zn SODs, normally associated with chloroplasts, have also been enhanced, resulting in improved cold tolerance in alfalfa (McKersie et al. 1999, 2000), salt and drought tolerance (Badawi et al. 2004b) in tobacco, and methyl viologen (MV-a superoxide-generating herbicide) tolerance in tobacco (Sen Gupta et al. 1993; Slooten et al. 1995) and poplar (Arisi et al. 1998). Other ROS scavenging enzymes have also attracted attention. Catalase over-expression in tobacco resulted in enhanced recovery from high light intensity and MV (Miyagawa et al. 2000), while expression of an ascorbate peroxidase gene resulted in protection against aminotriazole (but not paraquat)-induced oxidative stress (Wang et al. 1999) and heat stress (Shi et al. 2001) in Arabidopsis, and salt and drought stress in tobacco (Badawi et al. 2004a). A similar outcome was achieved through the overexpression of glutathione reductase in tobacco (Aono et al. 1993) and poplar (Foyer et al. 1995). Some investigators have extended the transgenic approach to explore simultaneous over-expression of more than one enzyme associated with ROS scavenging. Thus, Aono et al. (1995) crossed transgenic tobacco plants overexpressing SOD or GR and demonstrated a higher level of tolerance to
MV-induced oxidative stress in the hybrids, compared to that of either parent. Similarly, SOD and APX have proven an effective combination in transgenic tobacco (Kwon et al. 2002; Kim et al. 2005), potato (Tang et al. 2006) and tall fescue (Lee et al. 2007a). In one study with tobacco (Lee et al. 2007b) three components of the ROS defence network (SOD, APX and DHAR) were shown to provide further improvements in tolerance to salinity and $\mathrm{MV}$, in comparison with plants over-expressing only the first two of these.

All the above investigations proceeded through nuclear transformation, although most involved targeting of the recombinant enzyme to the chloroplast through the inclusion of a transit sequence. A convenient chloroplast transformation system for tobacco opens the way for the alternative strategy (hitherto unexplored) of examining the interplay of the various components of the ROS defences using direct expression in the chloroplasts. This negates any uncertainty about the efficiency of plastid targeting and, in the absence of any known mechanism for protein export from the chloroplasts, ensures we are exclusively gauging the consequences of over-expression in this organelle. We have embarked on a systematic investigation of the impact of increased activity of ROS scavenging enzymes through direct plastid transformation. The present report describes the results obtained for the first two target enzymes to be explored in this way, MnSOD and GR. SOD was chosen because of its key role in the first step of all the defence pathways, conversion of $\mathrm{O}_{2}{ }^{\bullet-}$ into $\mathrm{H}_{2} \mathrm{O}_{2}$, and the $\mathrm{Mn}$ form selected because, in contrast to the other isozymes, it is not sensitive to inactivation by its reaction product, $\mathrm{H}_{2} \mathrm{O}_{2}$ (Bowler et al. 1991). It has also proven an effective choice in previous over-expression studies carried out through nuclear transformation (e.g. McKersie et al. 1993; Tanaka et al. 1999; Van Breusegem et al. 1999). GR was an attractive choice because of its essential role in glutathione homeostasis, specifically in replenishing GSH in both the ascorbate-glutathione and glutathione peroxidase cycles (Mittler 2002).

\section{Materials and methods}

\section{Chloroplast transformation vectors}

The coding regions of $M n S O D$ and gor were cloned by PCR, using High Fidelity Taq polymerase (Clontech, Saint-Germain-en-Laye, France), and ligated initially into pCR2.1TOPO (Invitrogen, Paisley, Scotland, UK). PCR products were generated with the addition a NheI and $\mathrm{XbaI}$ restriction enzyme site at the $5^{\prime}$ and $3^{\prime}$ ends respectively. PCR products in recombinant clones were fully sequenced, and then the fragments were subcloned into the plastid transformation vector. Nicotiana plumbaginifolia manganese superoxide 
(A) ptDNA

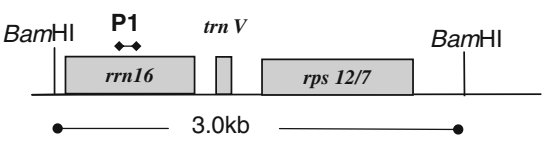

(B) pHK-MnSOD / pHK-GR

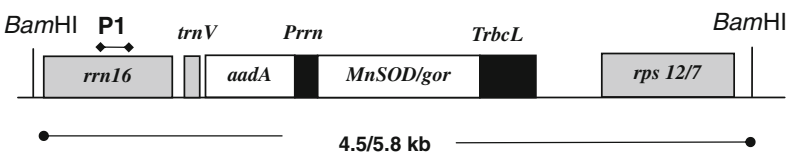

Fig. 1 Diagram of transgene expression cassettes inserted into tobacco chloroplast DNA. Map of wild type plastid DNA region of vector insertion and of plasmid pHK-MnSOD and pHK-GR. a Wild type plastid DNA showing the $16 \operatorname{SrDNA}$, $\operatorname{trn} V$ and $r p s 12 / 7$ genes along with position of BamH1 restriction sites relevant to the Southern blot. Location of the rrnl6 probe, P1 is shown. P1 hybridises to a $3.0 \mathrm{~kb}$ fragment in the wild type plants, and larger 4.5 and $5.8 \mathrm{~kb}$ fragments in the pHK-MnSOD and pHK-GR transplastomic lines respectively, when total genomic DNA is digested with BamH1. b Location of cloned flanking pieces of tobacco plastid DNA, with the selectable marker gene aadA and the position of the inserted MnSOD or gor downstream of the Prrn promoter. MnSOD or gor were cloned into Nheland Xbalsites of pHK34, replacing the neo coding region in each case. Coding regions were immediately downstream of the $3^{\prime}$ end of the coding region of the DB of $r b c L$ and driven by the Prrn promter. MnSOD or gor were followed by the $r b c L 3^{\prime}$ UTR $(\operatorname{TrbcL})$

dismutase (MnSOD), of $690 \mathrm{bp}$ length, excluding the chloroplast transit peptide sequence, was cloned from the plasmid pCHISOD (Bowler et al. 1991, obtained from Professor Dirk Inzé, Rijksuniversiteit Gent, Belgium) with the primers $5^{\prime}$-atgctagcgcactacgaaccctagtgagcaga- $3^{\prime}$ and $5^{\prime}$-gctctagatcaaggacattctttctcataaacttca- $3^{\prime}$. The Escherichia coli glutathione reductase (gor) sequence $(1.4 \mathrm{kbp})$ was cloned from E. coli genomic DNA with the primers $5^{\prime}$-cggctagcactaaacactatgattaca-3' and $5^{\prime}$-gctctagattaacgcca ttgtcacgaactcttc- $3^{\prime}$. The incorporated restriction sites allowed subcloning into the chloroplast transformation vector pHK34 (Kuroda and Maliga 2001), provided by P. Maliga, Rutgers University, USA, replacing the neomycin phosphotransferase (neo) coding region with $M n S O D$ or gor (Fig. 1).

Generation of transplastomic plants by particle bombardment

Gene delivery by particle bombardment and the selection process of transplastomic tobacco shoots (Nicotiana tabacum var Petit Havana) clones were performed essentially as described by Daniell (1997). Tobacco leaves were bombarded using a biolistic device (PDS-100/He; Bio-Rad, Hercules, CA). After bombardment, leaves were cut into approximately $25 \mathrm{~mm}^{2}$ explants and these were placed on RMOP medium (Svab et al. 1990) containing $500 \mathrm{~g} \mathrm{ml}^{-1}$ spectinomycin and green shoots were subcultured onto basal MS (Murashige and Skoog 1962) medium containing $500 \mathrm{~g} \mathrm{ml}^{-1}$ spectinomycin. Leaf pieces were placed under at least two rounds of regeneration before regenerated shoots reached homoplasmy. After homoplasmy was confirmed, transplastomic plants were moved to soil. Seed was collected from self-pollinated transgenic plants and used for further analysis.

\section{Southern blot analysis}

Southern blot analyses, using $10 \mu \mathrm{g}$ of BamHI digested genomic DNA, followed by chemiluminescent detection, were carried out as described by McCabe et al. (1997). The P1 probe $(700 \mathrm{bp})$ was generated with the primers $5^{\prime}$-aagccetggtaaggttcttc- $3^{\prime}$ and $5^{\prime}$-cgggttcgtgaacttctttc- $3^{\prime}$.

\section{Western blot of MnSOD and GR}

Concentration of extracted proteins was determined by a modified Bradford assay (1976) using the BioRad protein assay dye reagent. SDS-PAGE was carried out as described in Sambrook et al. (1989) followed by transfer of proteins to a nitrocellulose membrane (BioRad, Perth, Scotland, UK) (0.2 micron), on a Trans-Blot SD Semi-Dry Electrophoretic Transfer Cell (BioRad Perth, Scotland, UK). MnSOD was detected with a MnSOD polyclonal antibody raised in rabbits against recombinant $N$. plumbaginifolia MnSOD purified from yeast (Bowler et al. 1991), and kindly provided by Professor Dirk Inzé (Rijksuniversiteit Gent, Belgium). GR was detected with a rabbit polyclonal antibody against glutathione reductase, purchased from Lab Frontier (Seoul, Korea) diluted 1:2,000 in blocking buffer. The secondary antibody used was anti-rabbit IgG whole serum peroxidase conjugate (1:2,000 dilution in blocking buffer). Blots were then developed using the chemiluminescent detection system, Super Signal West Pico Kit (Pierce, Aalst, Belgium), according to the manufacturer's instructions, followed by exposure to Kodak X-ray film.

Leaf material

Leaf material used in all biochemical analyses and stress tests were taken from the 3rd and 4th nodes of 8-week old plants grown in growth rooms at $25^{\circ} \mathrm{C}$ under a $16 \mathrm{~h}$ photoperiod.

\section{SOD analyses}

This method was adapted from Chen and Pan (1996). Leaf tissue $(100 \mathrm{mg}$ ) was frozen in liquid nitrogen and ground to a fine powder in a microcentrifuge tube. Extraction buffer (0.15 M Tris, pH 7.5, 1\% (v/v) Tween 20, 0.5 mM EDTA) 
$(100 \mu \mathrm{l})$ was added and the tissue was ground again and vortexed for $1 \mathrm{~min}$. Samples were then centrifuged at $16,100 \times g$ for $15 \mathrm{~min}$ at $4^{\circ} \mathrm{C}$. The supernatant was transferred to a new microcentrifuge tube and centrifuged again at $16,100 \times g$ for $10 \mathrm{~min}$ at $4^{\circ} \mathrm{C}$ to clear any remaining debris. The supernatant was then kept on ice and immediately used for enzyme level determination or stored at $-20^{\circ} \mathrm{C}$ until further use.

Electrophoresis was carried out at $4^{\circ} \mathrm{C}$ under nondenaturing conditions according to Gabriel (1971) using a $13 \%$ separating polyacrylamide gel with a $4 \%$ stacking gel in standard tris-glycine buffer $(\mathrm{pH}$ 8.3). Samples were electrophoresed at $80 \mathrm{~V}$ through the stacking gel for $15 \mathrm{~min}$ and $120 \mathrm{~V}$ through the separating gel for $60 \mathrm{~min}$. The gel was then soaked in $25 \mathrm{ml}$ of buffer $1(1.23 \mathrm{mM}$ NBT in potassium phosphate buffer, $\mathrm{pH} \mathrm{7.0)} \mathrm{for} 15 \mathrm{~min}$, briefly washed in $\mathrm{dH}_{2} \mathrm{O}$, then soaked in $30 \mathrm{ml}$ buffer 2 (28 $\mathrm{mM}$ TEMED, $28 \mu \mathrm{M}$ riboflavin, in potassium phosphate buffer, $\mathrm{pH}$ 7.0), in the dark, with shaking at $75 \mathrm{rpm}$, for $15 \mathrm{~min}$. Gels were briefly washed in $\mathrm{dH}_{2} \mathrm{O}$ then illuminated on a light box with a light intensity of $30 \mu \mathrm{Em}^{-2} \mathrm{~s}^{-1}$ for $15 \mathrm{~min}$. Gels were then photographed using the SynGene gel viewing system. Band identification was according to Bowler et al. (1991).

\section{SOD activity}

This method was adapted from Chen and Pan (1996). Leaf tissue $(100 \mathrm{mg}$ ) was frozen in liquid nitrogen and ground to a fine powder in a microcentrifuge tube. $100 \mu$ extraction buffer (0.15 M Tris, pH 7.5, 1\% (v/v) Tween 20, $0.5 \mathrm{mM}$ EDTA) was added and the tissue was ground again and vortexed for $1 \mathrm{~min}$. Samples were then centrifuged at $13,000 \mathrm{rpm}$ for $15 \mathrm{~min}$ at $4^{\circ} \mathrm{C}$. The supernatant was transferred to a new microcentrifuge tube and centrifuged again at $13,000 \mathrm{rpm}$ for $10 \mathrm{~min}$ at $4^{\circ} \mathrm{C}$ to clear any remaining debris. The supernatant was then kept on ice and immediately used for enzyme level determination or stored at $-20^{\circ} \mathrm{C}$ until further use.

SOD activity was measured using the SOD Assay KitWST from Dojindo Molecular Technologies (MD, USA), following the manufacturer's instructions (www.dojindo. com/newimages/SODKitTechnicalInformation.pdf), with leaf extracts generated as described above.

Mn SOD specific activity was determined on the basis of cyanide insensitivity (Van Breusegem et al. 1999). Two millimolar KCN was added to the samples in the above assay.

Glutathione reductase assay

Leaf tissue $(100 \mathrm{mg})$ was homogenized in $500 \mu \mathrm{l}$ extraction buffer (100 mM potassium phosphate (pH 7.5), $1 \mathrm{mM}$
EDTA, $3 \mathrm{mM}$ DDT, 4\% (w/v) PVP) in a microcentrifuge tube on ice. The homogenate was filtered through Miracloth (Calbiochem) and centrifuged at $16,100 \times g$ for $30 \mathrm{~min}$ at $4^{\circ} \mathrm{C}$. The supernatant was collected and placed on ice for use immediately in enzyme assays or stored at $-80^{\circ} \mathrm{C}$. This assay was as described by Foster and Hess (1980), based on the reduction of glutathione (GSSG) by NADPH in the presence of glutathione reductase.

This reaction is measured by the decrease in absorbance at $340 \mathrm{~nm}$ using an extinction coefficient ( $\mathrm{cmM})$ of $6.22 \mathrm{mM}^{-1} \mathrm{~cm}^{-1}$ for NADPH. One unit of GR activity will cause the oxidation of $1.0 \mu \mathrm{mol}$ of NADPH at $25^{\circ} \mathrm{C}$ at $\mathrm{pH}$ 7.5. The extracts were used in this assay immediately after extraction. To measure enzyme activity of samples the following were placed into a $1 \mathrm{ml}$ quartz cuvette: $2 \mathrm{mM}$ oxidized glutathione $(500 \mu \mathrm{l})$, Assay buffer $(1 \mathrm{mM}$ EDTA, $100 \mathrm{mM}$ potassium phosphate buffer, $\mathrm{pH}$ 7.5) $(400 \mu \mathrm{l})$, sample extract $(50 \mu \mathrm{l})$, and $2 \mathrm{mM}$ NADPH $(50 \mu \mathrm{l})$. The blank consisted of all components listed above except $450 \mu \mathrm{l}$ Assay buffer was used and no extract was added. The reaction components were mixed by inversion and the absorbance of the sample was read at $340 \mathrm{~nm}$ for $2 \mathrm{~min}$ at $10 \mathrm{~s}$ intervals. The amount of enzyme in the sample was calculated using the following formula:

$$
\begin{aligned}
\mathrm{GR}(\text { units } / \mathrm{ml})= & \text { (rate of change of sample } \\
& - \text { rate of change of blank }) \\
& \times 6.22 \mathrm{mM}^{-1} \mathrm{~cm}^{-1} \\
& \times(\text { volume of sample in } \mathrm{ml}) .
\end{aligned}
$$

\section{Methyl viologen (MV-Paraquat) treatment}

Leaf discs (6) of $1.5 \mathrm{~cm}$ diameter were cut out of leaves from the 3rd and 4th nodes of soil-grown plants and floated on distilled water. Each disc was then floated individually, abaxial surface down, on $6 \mathrm{ml}$ of water or solutions containing various concentrations of paraquat $(0-100 \mu \mathrm{M})$ in $35 \mathrm{~mm}$ Petri dishes. Leaf discs were then incubated in the dark for $4 \mathrm{~h}$ at $23^{\circ} \mathrm{C}$. Leaf discs were then placed under a white light source for $48 \mathrm{~h}$ with a light intensity of $12 \mu / \mathrm{m}^{2} / \mathrm{s}$. Leaf discs were photographed after 24 and $48 \mathrm{~h}$, followed by chlorophyll and electrolyte leakage measurements. Leaf discs (6) were taken from three individual plants of each independent line examined and the assay was repeated three times.

\section{Chlorophyll analysis}

Chlorophyll was extracted by soaking leaf discs $(1.5 \mathrm{~cm}$ in diameter) in $3 \mathrm{ml}$ of $100 \%$ methanol for $24 \mathrm{~h}$. The absorbance (A) of the $3 \mathrm{ml}$ solution was then measured spectrophotometrically at 665.2 and $652.4 \mathrm{~nm}$. Total chlorophyll was calculated using the following 
equation: Total Chlorophyll $(\mu \mathrm{g} / \mathrm{ml}$ plant extract solution) $=1.44 \mathrm{~A}_{665.2}-24.93 \mathrm{~A}_{652.4}$

\section{Electrolyte leakage measurement}

The electrical conductance of the paraquat solutions $\left(C_{\text {initial }}\right)$ retained was measured using a conductivity meter (EC215 Conductivity Meter, Hanna Instruments, UK) after the $48 \mathrm{~h}$ light treatment. To measure total ion leakage $\left(C_{\max }\right)$, leaf discs were autoclaved at $120^{\circ} \mathrm{C}$, for $20 \mathrm{~min}$, in their respective solutions and electrical conductance was measured again. Relative electrolyte leakage (EL) was calculated as a percentage: $\mathrm{EL}=C_{\text {initial }} / C_{\max } * 100$.

\section{Ultraviolet (UV-B) radiation exposure}

UV treatments consisted of exposure of tobacco leaf discs to UV radiation, generated by Philips TL12 fluorescent tubes $\left(\lambda_{\max } 315 \mathrm{~nm}\right)$. Leaf discs were exposed to $4.4 \mathrm{~W} / \mathrm{m}^{2}$ radiation for $16 \mathrm{~h}$, resulting in a total dose of $253 \mathrm{~kJ} / \mathrm{m}^{2}$. This dose used is unnaturally high (several times that in the southern Europe Mediterranean region) as it was used to probe for potential increases in protection (rather than to do environmental work). The data cannot be directly extrapolated to specific environments as there was no PAR present during the UV-B exposure. The bulb output was filtered through a single layer of cellulose acetate to eliminate UV-C radiation. The irradiance level represents radiation in the spectral range between 295 and $345 \mathrm{~nm}$. Discs were floated on distilled water, with their adaxial side facing the UV source. The decrease in photosynthetic activity was attributed to the UV-B wavelength since the low level of UV-A radiation is ineffective in decreasing chloroplast photosystem II (PSII) activity (Herrmann et al. 1997). Tadić et al. (2001) compared the UV-A and UV-B emitted by TL12 tubes, and showed most emission was in the UV-B range. No additional PAR (photosynthetically active radiation) was applied during the UV treatment. UV levels were measured using a PMA2200 UV-meter (Solar Light Co., Philadelphia, USA). The severity of the stress was assessed by measuring the photosynthetic efficiency of PSII using the saturating pulse fluorescence technique using an imaging PAM (Walz, Effeltrich, Germany). After UV treatments, leaf discs were placed in the dark for at least $30 \mathrm{~min}$ before efficiency of PSII was measured. The minimal fluorescence $\left(F_{0}\right)$, maximal fluorescence $\left(F_{\mathrm{m}}\right)$, and the variable fluorescence $\left(F_{\mathrm{v}}=F_{\mathrm{m}}-F_{0}\right)$ were all measured according to van Kooten and Snel (1990). The photochemical yield of open PSII reaction centres, commonly known as the relative variable fluorescence, was calculated as $F_{\mathrm{v}} / F_{\mathrm{m}}$ as a reflection of the maximal efficiency of PSII. In individual experiments, sampling consisted of 5 discs from three plants per independent line. Overall the experiment was repeated on three occasions.

Effect of cadmium on seed germination

Seed from non-transgenic wild type (WT) and transformed lines were harvested from self pollinated plants grown in soil in growth rooms. Seeds were surface sterilized, and 20 seeds of each line were then placed into sectors on petri dishes containing seed germination medium. Plates were divided into 6 equal sections in the case of GR transformants or 4 sections for MnSOD transformants and seed from all transformed lines from a given gene construct and WT control seeds were placed in rows on a single plate in order to ensure all seeds were treated identically. Triplicate plates were made for each treatment, and three separate experiments were conducted. To test heavy metal tolerance, germination medium containing 0 or $0.5 \mathrm{mM}$ Cadmium(II), added to germination medium as $\mathrm{CdCl}_{2}$, was used. These plates were wrapped in foil and placed at $23^{\circ} \mathrm{C}$ for 7 days, after which the foil was removed and plates were then grown in the light for a further 14 days then scored for $\%$ germination and photographed.

Statistical analysis

All data are presented as mean (and standard error of the mean). Statistical analysis was performed by one-way analysis of variance (ANOVA). Post-hoc tests used were either Dunn's or Kruskal-Wallis. Significance level is indicated separately for each experiment.

\section{Results}

Transgenic plants expressing $M n S O D$ and gor in chloroplasts

Chloroplast transformants from biolistic transformations were identified by PCR. Three out of 24 spectinomycin resistant shoots regenerated from shots with $\mathrm{pHK}-\mathrm{MnSOD}$ were positive for MnSOD by PCR (data not shown), designated as Mn1, Mn2 and Mn6. Similarly, 5 GR transformants, positive for gor integration in the plastid genome, were found from 18 spectinomycin resistant shoots regenerated from $\mathrm{pHK} 34-\mathrm{GR}$ transformations (data not shown), designated GR14, 17, 18, 19 and 20. After two further rounds of tissue culture regeneration on spectinomycin containing medium, genomic DNA was isolated from these 8 shoots and digested with BamHI restriction enzyme. Transplastomic plants were confirmed by Southern blot with the DIG-labelled P1 probe (700 bp) (Fig. 2). Whilst WT tobacco showed a $3.0 \mathrm{~kb}$ hybridising band, the 
Fig. 2 Southern blots of BamHI digested DNA. Genomic DNA was digested with $\mathrm{BamHI}$ and hybridised with the $700 \mathrm{bp}$ flanking sequence probe P1

(Fig. 1). a pHK-MnSOD transformants. The major hybridizing fragments are at $3.0 \mathrm{~kb}$ in WT and $4.5 \mathrm{~kb}$ in MnSOD lines. b pHK-GR transformants. The major hybridising fragments are at $3.0 \mathrm{~kb}$ in WT and $5.2 \mathrm{~kb}$ in pHK-GR transformants. MW: DNA size marker

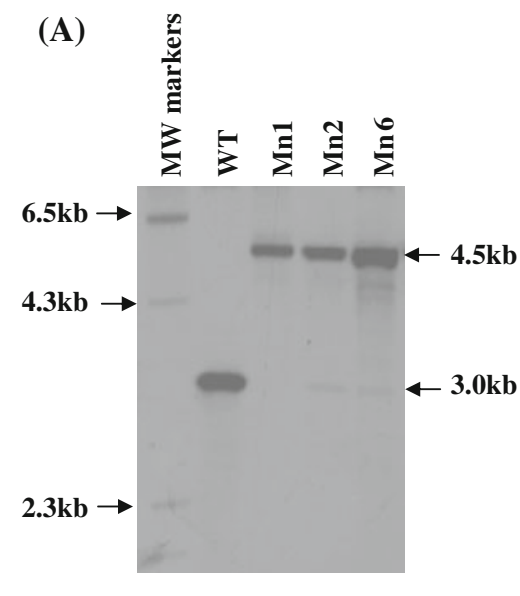



P1 probe hybridised to 4.5 (Fig. 2a) and $5.8 \mathrm{~kb}$ (Fig. 2b) bands in the MnSOD and GR transformants respectively. Southern blot analysis confirmed the correct integration of the vector cassette into the plastome and that the plastome of the transformed lines Mn1, 2, and 6 and GR14, 17, 18, 19 and 20 reached the homoplasmic state, in that no WT plastome copies remained after three regeneration cycles on selection medium. WT and transformed plants were transferred to soil and grown to the eight-week stage in growth rooms.

\section{Enzyme analyses}

MnSOD and GR protein expression were confirmed by immunoblot analysis of protein extracts separated by SDSPAGE. The MnSOD antibody detected two polypeptides. Similar amounts of native $N$. tabacum MnSOD were immunologically detected in $50 \mu \mathrm{g}$ of both WT and transgenic Mn1 soluble leaf extracts as the expected $20 \mathrm{kDa}$ band, while the engineered $N$. plumbaginifolia MnSOD, which was detected in the $T_{1}$ generation of transgenic line, Mn1 as the expected $22 \mathrm{kDa}$ band (Fig. 3a), due to its fusion to the coding region of the 14 amino acids in pHK34 and not in the wild-type. The engineered $N$. plumbaginifolia MnSOD transgenic band was however, present at a greater intensity than the wild type band representing a significant elevation of the engineered MnSOD protein over the native MnSOD protein.

Expression of the E. coli gor was analysed in $20 \mu \mathrm{g}$ soluble leaf extracts from the T2 generation of each GR transgenic line. The recombinant GR was increased by $2 \mathrm{kDa}$ compared to the native form as a result of the cloning into pHK34. The additional amino acids however did not affect the functional integrity of the protein. Western blots confirmed the presence of the GR protein of the predicted molecular weight, $50 \mathrm{kDa}$, in leaf extracts of the primary transformants and the T2 generation of each GR transgenic line (Fig. 3b).
The different SOD isoforms were detected by SODactivity staining of soluble leaf proteins on polyacrylamide gels under non-denaturing conditions (Fig. 3,

(A)



(B)
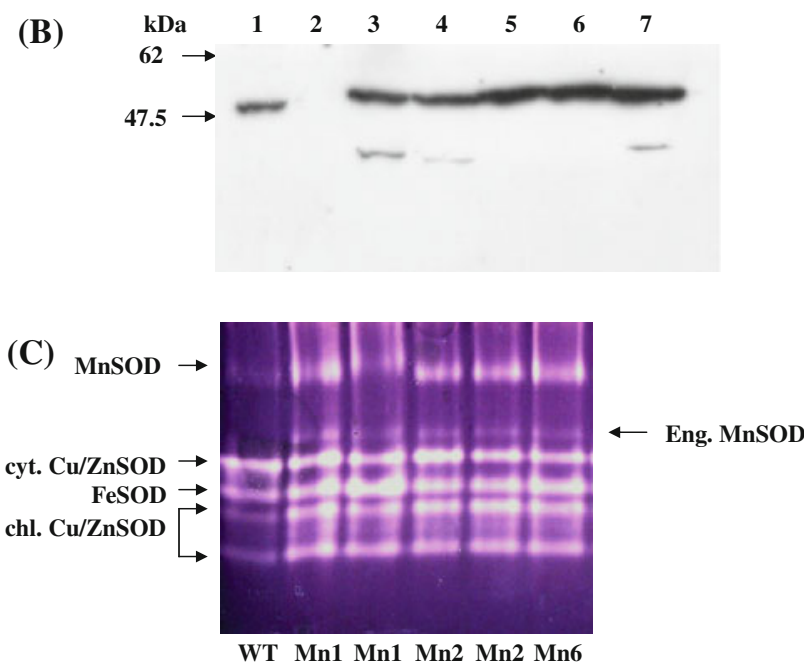

Fig. 3 Expression of MnSOD or GR in transgenic tobacco leaves. a Immunodetection of MnSOD in total soluble protein extracts $(50 \mu \mathrm{g})$ of a WT and the Mn1 $\left(\mathrm{T}_{1}\right)$ transgenic plant. b Immunodetection of glutathione reductase $(G R)$ in total soluble protein extracts $(20 \mu \mathrm{g})$ of WT and $\mathrm{T}_{2}$ of five plastid transformed tobacco lines. Lane 1 positive control, protein extracted from E. coli line pHK-GR (see Fig. 1), lane 2 WT, lane 3-7 lines GR14, GR17, GR18, GR19 and GR20 respectively. c Native gel showing major SOD isoforms in non-transformed line (WT) and Nicotiana plumbaginifolia MnSOD expression in transgenic plants tested by activity staining of non-denaturing polyacrylamide gel. The unique band for engineered, plastid expressed MnSOD was only present in MnSOD transgenic plants 
Bowler et al. 1991). A characteristic SOD isoenzyme banding pattern was found for WT tobacco, consisting of two quickly migrating chloroplastic $\mathrm{Cu} / \mathrm{ZnSOD}$ activity bands, a slower migrating FeSOD and cytoplasmic $\mathrm{Cu} / \mathrm{ZnSOD}$, and a much slower migrating MnSOD band (Fig. 3c). In transplastomic lanes a more slowly migrating band was also present corresponding to the engineered MnSOD. Native gel analysis also indicated that cytoplasmic $\mathrm{Cu} / \mathrm{ZnSOD}$ exhibited similar intensities in both the WT and transplastomic lines, but the latter had greatly increased native MnSOD and chloroplast $\mathrm{Cu} / \mathrm{ZnSOD}$. FeSOD also increased, but to a lesser degree, in the three transgenics (Fig. 3c).

SOD enzyme activity was also determined spectrophotometrically. The activity of the endogenous MnSOD in the WT was low, however its activity was higher in transplastomic plants. The engineered MnSOD was present only in transplastomic lines and at equal levels of activity. In primary transformants, line $\mathrm{Mn} 1$, showed a ninefold increase in total SOD activity over WT SOD activity and line Mn2 and Mn6, showed a fivefold increase in total SOD activity over WT (data not shown). These increases were confirmed in the $\mathrm{T} 1$ generation for each transplastomic line (Fig. 4). Each transplastomic line showed an average threefold increase in MnSOD specific activity. Therefore, differences in total SOD activity of the transplastomic lines were not due solely to differing levels of MnSOD activity but had a contribution from increased activity of the endogenous SODs.

\section{Glutathione reductase and glutathione analyses}

GR activity was expressed as nmol NADPH oxidised per min per $\mathrm{mg}$ of protein for the $\mathrm{T} 1$ progeny of each independently transformed GR line. The GR levels in leaf extracts of plants transformed with gor were substantially higher than the wild type control (Fig. 5a). Transgenic lines GR14 and GR17 had GR levels 6 times higher than



Fig. 4 Superoxide disumutase (SOD) activity in T1 transplastomic plants. Figure represents an estimation of total SOD and Mn specific activities in leaves of MnSOD transgenics compared to WT plants. Vertical bars represent standard errors $(n=3$ per experiment). All the values for the transplastomic lines differ significantly different from those of the WT plants $(P \leq 0.05)$
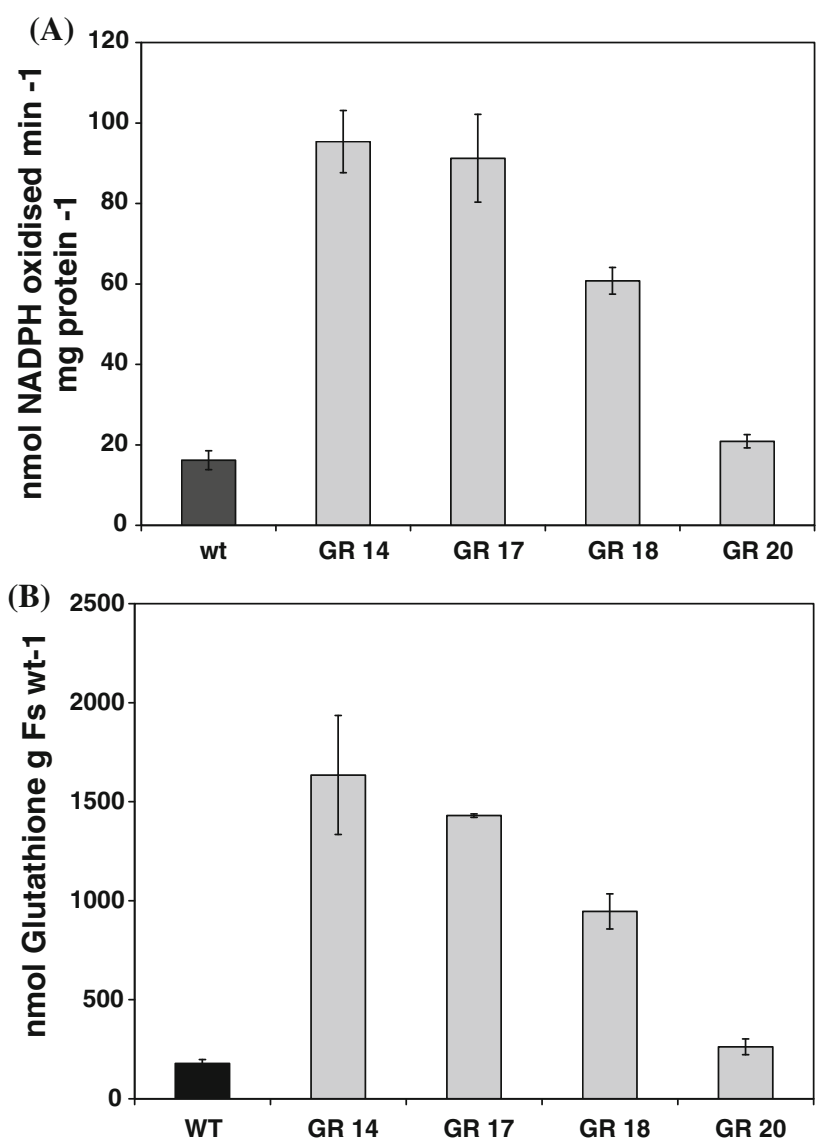

Fig. 5 Glutathione reductase and total glutathione content estimated from leaf samples of pHK-GR plants. a GR activity as measured by NADPH oxidation rate. b Total glutathione content of WT and transgenic lines. Error bars indicate $( \pm) \mathrm{SE},(\mathrm{n}=3$ per experiment). All values for transgenic plants are significantly different from the WT $(P \leq 0.05)$

WT. GR activity in GR18 and GR20 were 4 and 1.3 times higher respectively, than in the WT. Even the small increase detected in line GR20 was statistically significant $(P<0.001)$. Because GR maintains the levels of cellular glutathione, total glutathione levels were also measured. The increase in GR activity in each transgenic line corresponded to the increase in total glutathione, with GR14 and GR20 increased by 8.3 and 1.8 times respectively compared to WT glutathione levels (Fig. 5b).

Effect of MV treatment on chlorophyll and electrolyte levels

The efficacy of increased expression of MnSOD or GR in tobacco chloroplasts in mediating resistance to oxidative stress was evaluated using MV treatment, with the extent of cellular damage indirectly measured by electrolyte leakage to indicate the extent of membrane rupture. MnSOD transplastomic and WT leaf discs were floated on MV concentrations ranging from 0 to $100 \mu \mathrm{M}$. WT leaf discs 
Fig. 6 Photo-oxidative stress $(M V)$ tolerance of leaves of transgenic MnSOD plants. a Chlorophyll retention after MV treatment. Chlorophyll was measured in WT and transgenic leaf discs $48 \mathrm{~h}$ after treatment and compared to leaf discs floated on water only. Values are the percentage chlorophyll retained in relation to chlorophyll content of freshly cut leaf discs prior to incubation. The experiments were repeated three times and data are means of three independent measurements. Standard errors were all less than $10 \%$ of the mean and leaf discs of all Mn transgenics retained significantly more chlorophyll than WT $(P<0.001)$. b Electrolyte leakage. Leaf discs were floated on solutions containing the indicated concentrations of paraquat, pre-incubated in the dark for $2 \mathrm{~h}$, and then exposed to light of $150 \mu \mathrm{mol}$ photons $\mathrm{m}^{-2} \mathrm{~s}^{-1}$ for $24 \mathrm{~h}$ at $25^{\circ} \mathrm{C}$. Conductivities of the floatation solutions were measured and expressed as percentages of the conductivity values obtained after total cell lysis by autoclaving the samples
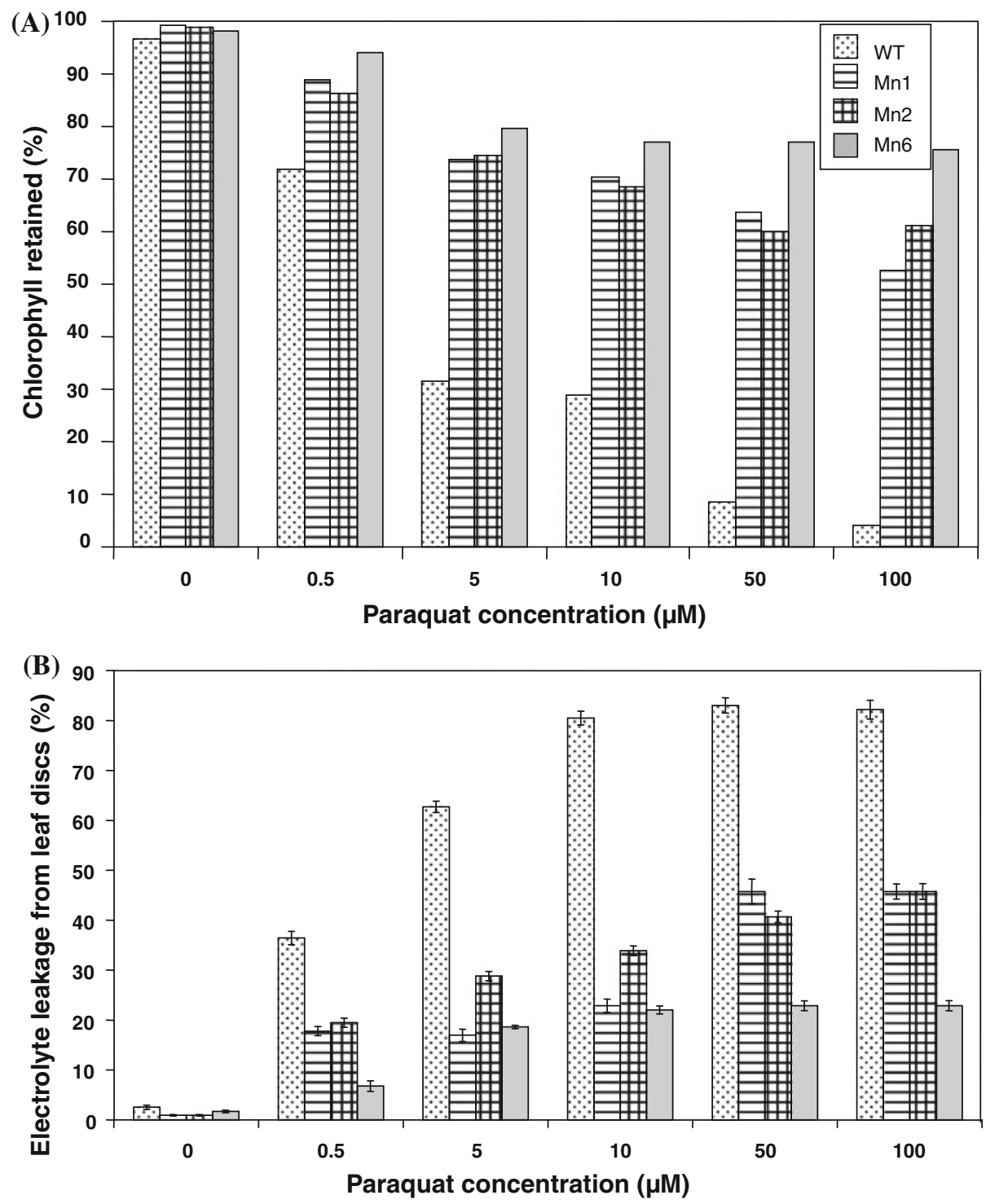

were strongly bleached by all levels of MV from $5.0 \mu \mathrm{M}$ upwards, while all three transplastomic MnSOD lines retained more than $50 \%$ of their chlorophyll even at $100 \mu \mathrm{M}$ MV (Fig. 6a). MV induced approximately 80\% electrolyte leakage in WT leaf discs at a concentration of $10 \mu \mathrm{M}$, while Mn1 and Mn6 had approximately $20 \%$ electrolyte leakage and Mn2 had approximately 30\% electrolyte leakage (Fig. 6b). Even at the highest concentration of MV tested, $100 \mu \mathrm{M}$, lines Mn1 and Mn2 had lost less than $40 \%$ of their electrolytes while Mn6 showed an even greater MV tolerance, having only a $20 \%$ loss.

GR lines did not have increased protection from photooxidative stress due to MV treatment. Leaves of the same age were sampled and floated on a more limited range of MV concentrations, indicative of the fact that GR transgenic lines as a whole had a greater sensitivity to MV. At a concentration of $5 \mu \mathrm{M}$, chlorophyll degradation was visible in the GR lines after $24 \mathrm{~h}$ of MV treatment (Fig. 7a), at which point there was little chlorophyll loss in the wild type discs. By $48 \mathrm{~h}$ all lines exhibited substantial chlorophyll loss, but the GR lines retained less chlorophyll than WT at $5 \mu \mathrm{M}$, indicating greater sensitivity to MV stress (Fig. 7b). When electrolyte leakage was measured, no significant difference in the percent of leakage was seen between GR14, GR20 and WT. However, electrolyte leakage of GR17 and GR18 were significantly greater $(P<0.001)$ than WT (Fig. 7c). The inter-line variation in sensitivity to MV was not correlated with the increase in GR activity or total glutathione levels, as described in Fig. 5.

\section{Differences in UV-B sensitivity in Mn and GR} transgenic plants

Leaf discs were exposed to UV-B radiation and its effect on the photosynthetic efficiency of PS II was measured. Leaf discs were exposed to UV-B radiation and initial 



Fig. $7 \mathrm{MV}$ treatment of pHK-GR leaf discs. a Representative image showing phenotypic differences of GR 18 transgenic line and WT leaf discs floated on a 5 and $10 \mu \mathrm{M}$ paraquat solution for $24 \mathrm{~h}$. b Percentage chlorophyll retetention in leaf discs of WT and transgenic plants floated for $48 \mathrm{~h}$ on 0.5 and $5 \mu \mathrm{M}$ paraquat solutions. Chlorophyll was measured in transgenic leaf discs $48 \mathrm{~h}$ after treatment and compared to chlorophyll contents of leaf discs floated on water only. The experiments were repeated three times and data are means \pm standard error of three independent measurements. Wild type plants retained significantly more chlorophyll than GR transgenics after MV treatment $(P<0.001)$. c Relative electrolyte leakage from leaf discs of WT and transgenic plants floated on a $5 \mu \mathrm{M}$ paraquat solution. The relative electrolyte leakage of transgenic leaf discs was measured $48 \mathrm{~h}$ after treatment and compared to the electrolyte leakage of WT control leaf discs. The experiments were repeated three times and data are means \pm standard error of three independent measurements. Significant differences in electrolyte leakage existed between wild type and GR17 and GR18 $(P<0.001)$. No significant differences were seen between the WT and GR14 or GR20 $(P>0.05)$

experiments were conducted to determine the conditions under which exposure to UV-B induced a significant change in $F_{\mathrm{v}} / F_{\mathrm{m}}$ in WT and transgenic leaf discs. Leaf discs were exposed to $4.4 \mathrm{~W} / \mathrm{m}^{2} \mathrm{UV}$ radiations and the $F_{\mathrm{v}} / F_{\mathrm{m}}$ was measured at 4, 6, 8, 16, and $24 \mathrm{~h}$. An exposure time of $16 \mathrm{~h}$ to UV-B was chosen because it was at this time point that significant changes in $F_{\mathrm{v}} / F_{\mathrm{m}}$ of WT leaf discs were observed. The $16 \mathrm{~h}$ exposure results in a total dose of $253 \mathrm{~kJ} / \mathrm{m}^{2}$.

Prior to UV-treatment, the $F_{\mathrm{v}} / F_{\mathrm{m}}$ values were very similar as discussed above. However exposure to $4.4 \mathrm{~W} / \mathrm{m}^{2}$ UV-B radiation for $16 \mathrm{~h}$ resulted in significant differences in $F_{\mathrm{v}} / F_{\mathrm{m}}$ values between WT and transgenic lines. WT leaf discs showed a $21 \%$ decrease in $F_{\mathrm{v}} / F_{\mathrm{m}}$ and the degree to which the $F_{\mathrm{v}} / F_{\mathrm{m}}$ of wild type and $\mathrm{Mn}$ transgenic lines were affected by UV-B was extremely significant $\left(P=3.4324 \times 10^{-8}\right)$ (Fig. 8a). No statistical difference was observed in the change in $\mathrm{Fv} / \mathrm{Fm}$ among Mn transgenic lines; exposure of leaf discs of all Mn transgenic lines resulted in a 9\% decrease in $F_{\mathrm{v}} / F_{\mathrm{m}}$ (Fig. 8a). Similar results were observed in the GR transgenic lines in that no significant differences were seen in UV-B tolerance between the GR lines (Fig. 8b), however due to greater variation in individual measurements, results were less significant $(P=<0.001)$ than the effect seen in Mn lines. The leaves of all GR plants tested resulted in an $8.2 \%$ decrease in $F_{\mathrm{v}} / F_{\mathrm{m}}$ which is not statistically different from the Mn transgenic lines tested, however it is a substantial improvement over the $21 \%$ decrease in WT $F_{\mathrm{v}} / F_{\mathrm{m}}$ (Fig. $8 \mathrm{~b}$ ).

Effect of cadmium on transgenic tobacco plants

Heavy metal tolerance of $\mathrm{T} 1$ generation transgenic seeds was examined by germinating seeds on germination medium containing up to $0.5 \mathrm{mM}$ cadmium $(\mathrm{Cd})$. Only seeds that germinated and continued to grow into seedlings on $\mathrm{Cd}$ containing medium were considered fully germinated (Fig. 9a). In the absence of cadmium, WT and transgenic Mn and GR lines showed 100\% germination (Fig. 9b), but germination of WT and MnSOD seeds was reduced by at least $80 \%$ at $0.5 \mathrm{mM} \mathrm{Cd}$. MnSOD transgenic lines germinated poorly on cadmium containing medium, with an average germination of $14 \%$. However, all five transgenic GR lines showed significantly higher seedling germination percentages over WT and Mn transgenic lines (Fig. 9a, b). Only $23 \%$ of wild type seeds germinated on $0.5 \mathrm{mM}$ cadmium containing medium, but over $94 \%$ of seeds germinated in lines GR17, GR19, and GR20.

\section{Discussion}

This report describes the stable integration and expression of genes encoding two enzymes associated with the scavenging of reactive oxygen species in the chloroplasts of tobacco plants. Immunblots and an activity gel confirmed the presence and activity of recombinant MnSOD. Total SOD activity was increased sixfold to tenfold in transplastomic lines but much of this was down to an 

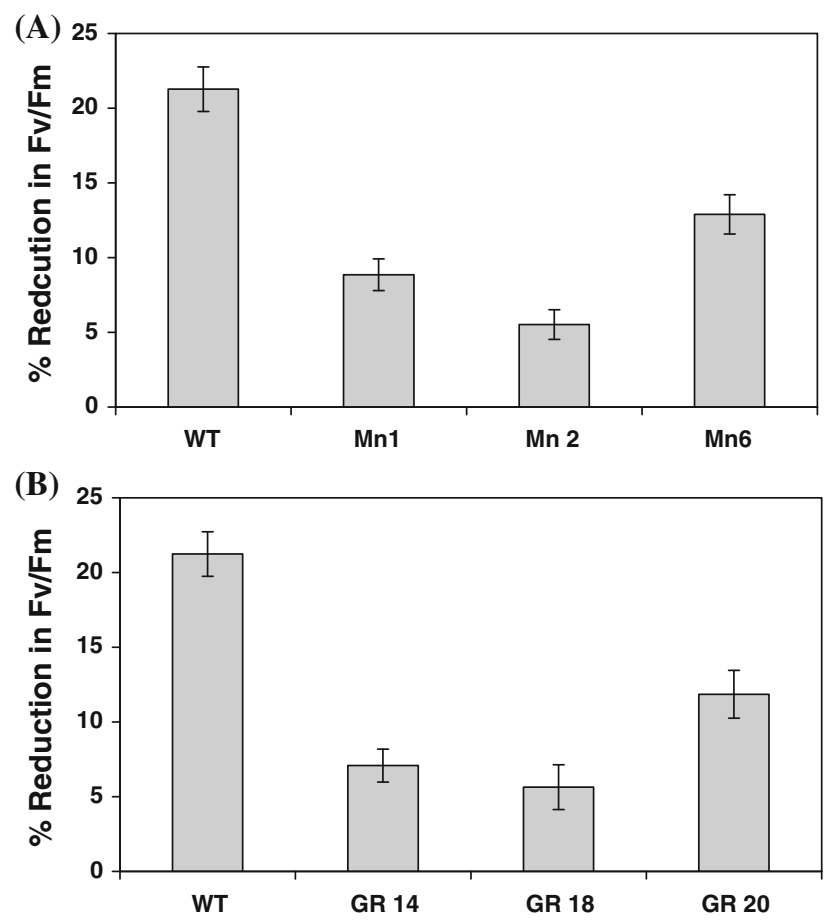

Fig. 8 Effects of UV-B radiation on the reduction of relative variable fluorescence of wild type and transgenic leaf tissue. Plants were grown in soil in a glass house for 8 weeks. Leaf discs $(1 \mathrm{~cm}$ in diameter) were excised from leaves of nodes 3 and 4 . The minimal fluorescence $\left(F_{0}\right)$ and maximal fluorescence $\left(F_{\mathrm{m}}\right)$ were measured on dark adapted samples. Photosynthetic efficiency of PS II was measured as the relative variable fluorescence $F_{\mathrm{v}} / F_{\mathrm{m}}$, where $F_{\mathrm{v}}=F_{\mathrm{m}}-F_{0}$. Leaf discs were then exposed to $4.4 \mathrm{Wm}^{-2} \mathrm{UV}$ radiation for $16 \mathrm{~h}$. Following UV treatment, $F_{\mathrm{v}} / F_{\mathrm{m}}$ was measured again. The relative variable fluorescence was normalized to that of the non-treated control (WT $100 \%=0.692 \pm 0.01$ ). a Variable fluorescence of UV-B treated WT and pHK-MnSOD plants. Values represent averages of 40 measurements. Error bars represent standard error of the means. Statistical analysis (Kruskal-Wallis ANOVA) revealed significant differences between $\mathrm{Mn} 1, \mathrm{Mn} 2, \mathrm{Mn} 6$, and the WT control $\left(P=3.4324 \times 10^{-8}\right)$. According to Dunn's Multiple Comparisons test, no significant differences exist between the three Mn lines. b Variable fluorescence of UV-B treated WT and pHK-GR plants. Statistical analysis (Kruskal-Wallis ANOVA) revealed significant differences between GR14, GR18, GR20 and the WT control $(P<0.05)$

unexpected elevation of several of the native SOD isozymes. Increases in MnSOD specific activity were much smaller; threefold to fourfold in an isoenzyme generally regarded as of relatively low abundance (Van Camp et al. 1997). The bands that are increased in activity correspond to all the organellar SODs (mitochondrial MnSOD, chloroplastic $\mathrm{Cu} / \mathrm{ZnSOD}$ and $\mathrm{FeSOD}$ ), while the cytosolic $\mathrm{Cu} / \mathrm{ZnSOD}$ activity is unaffected. This finding runs counter to some previous observations (e.g. Slooten et al. 1995, McKersie et al. 1999, Kwon et al. 2002), on nuclear transformants, which suggest that over-expression of chloroplast-targeted SODs suppresses the activity of the native enzymes, although this finding is far from universal among the various SOD over-expressing lines. In fact there are two publications which support our observation. Van Breusegem et al. (1999) expressed tobacco MnSOD in maize chloroplasts and published a densitogram of the SOD banding pattern of their plants (Fig. $2 \mathrm{c}$ in their paper) which clearly shows elevated activity of all the SOD isoenzyme activities except one, in their transgenic plants. Lee et al. (2007b), reporting on plants simultaneously expressing 2 or 3 ROS scavenging enzymes (including SOD) published an activity gel where there is clear enhancement of an unidentified native SOD (possibly FeSOD on the basis of its proximity to the engineered $\mathrm{Cu} / \mathrm{Zn}$ enzyme). Curiously the authors of neither paper allude to this interesting finding which, together with our results, suggests redox-mediated retrograde signalling between the chloroplasts and the nucleus. A signalling role of ROS from the chloroplasts, involving induction of nuclear genes encoding defence related proteins, is well established (reviewed in Nott et al. 2006; Pfannschmidt et al. 2009), with $\mathrm{H}_{2} \mathrm{O}_{2}$ as the prime candidate. Excess $\mathrm{H}_{2} \mathrm{O}_{2}$, produced by stress (or in our case elevated SOD activity) can diffuse from the chloroplast and, probably through mitogen-activated protein kinases (Kovtun et al. 2000), trigger expression of nuclear encoded defence-related genes such as $C A P X$ encoding an ascorbate peroxidise (Kimura et al. 2001), Cat encoding catalase and Gstl encoding Glutathione-S-transferase (Polidoros and Scandalios 1999), as well (in the $\mathrm{C}_{3}$-CAM transition species Mesembryanthemum crystallinum) as genes encoding $\mathrm{Cu} / \mathrm{Zn}-, \mathrm{Mn}-$, and Fe-SOD (Slesak et al. 2003). The current results suggest that increases in $\mathrm{H}_{2} \mathrm{O}_{2}$ levels caused by chloroplastic expression of MnSOD, mimic abiotic and biotic stress responses, leading to a similar MAPK induced expression of nuclear-encoded defence proteins, including several organellar SODs, in these transplastomic tobacco lines. Thus the altered levels of oxidative stress tolerance observed are probably not solely the direct result of MnSOD expression in the chloroplasts.

Transplastomic plants expressing MnSOD exhibit substantial increases in tolerance to MV (Paraquat)-induced oxidative stress, as assessed by chlorophyll and electrolyte leakage measurements. This finding is consistent with most of the studies in which plastid SOD levels have been achieved through nuclear transformation and plastid targeting (see Introduction). There are occasional exceptions (e.g. Cu/ZnSOD, Tepperman and Dunsmuir 1990) where no increase in oxidative stress tolerance was achieved in SOD over-expressing plants. Such discrepancies attest to the complexity of the interactions between ROS scavenging enzyme levels (SOD, ascorbate peroxidase, mono- and dehydroascorbate reductase, glutathione-reductase, -peroxidase and -transferase etc), the quantity and redox state of their substrates (ascorbate, glutathione), and the actual 
(A)
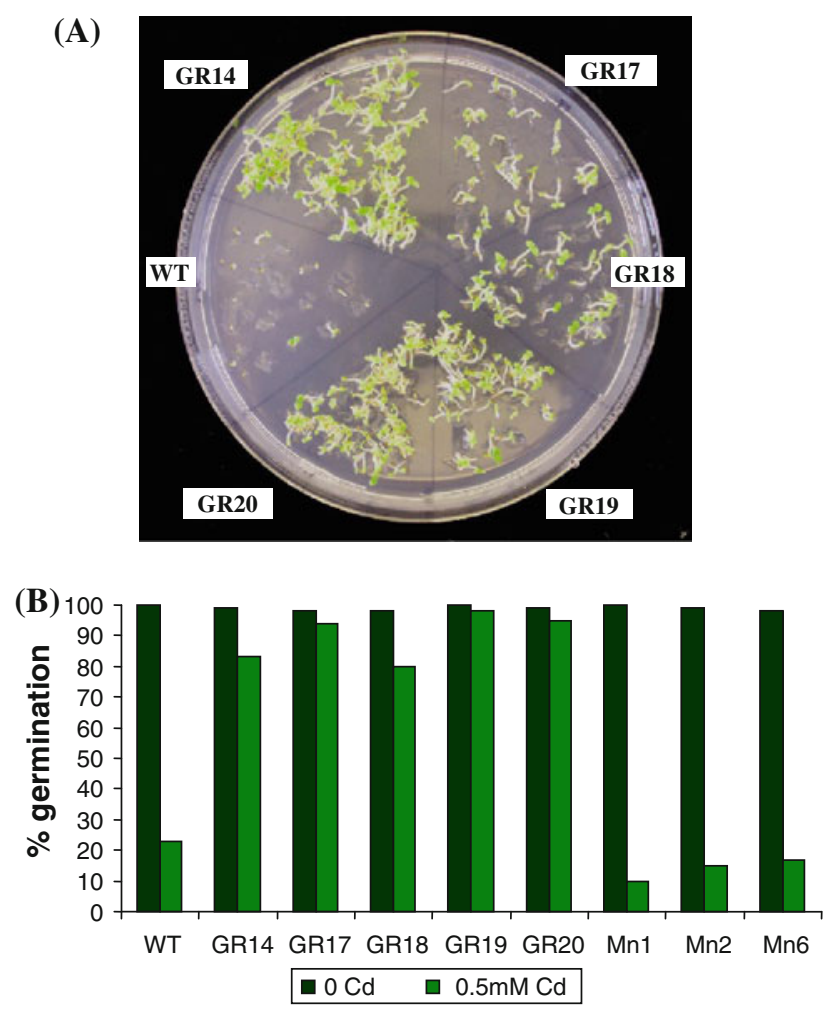

Fig. 9 Cadmium tolerance test of T1 generation tobacco seedlings overexpressing either glutathione reductase or MnSOD. Seeds of wild type and transgenic lines were germinated on $0.5 \times$ MS medium supplemented with $0.5 \mathrm{mM}$ cadmium and grown for 14 days. Approximately 50 seeds of each line were plated out in triplicate in three different experiments. a Representative test of T1 generation GR seeds. b Seed germination and seedling growth after cadmium treatment. Percent of seed that germinated and developed into seedlings on $0.5 \mathrm{mM} \mathrm{Cd}$ containing germination medium of total number of wild type and transgenic seeds tested. All standard errors were less than $10 \%$ of the mean. GR lines showed increased tolerance to $\mathrm{Cd}$. Mn transgenic lines had no increased tolerance to $\mathrm{Cd}$

levels of the individual ROS themselves (some of which are known to have signalling roles), further complicated by the intracellular compartmentation of the enzymes, metabolites and ROS. The consequences of altering an individual component are difficult to predict. For example, Bowler et al. (1991) observed that while large increases in chloroplast MnSOD levels increased oxidative stress tolerance, smaller increases were actually deleterious. Tepperman and Dunsmuir (1990) achieved particularly high expression levels without enhancement of oxidative stress tolerance, but were using a $\mathrm{Cu} / \mathrm{ZnSOD}$ which, in contrast to $\mathrm{MnSOD}$, is sensitive to the $\mathrm{H}_{2} \mathrm{O}_{2}$ generated.

Similar unpredictability is manifest in the oxidative stress response of glutathione reductase (GR) overexpressing transplastomic plants, in which increased GR activity led to increased oxidative stress sensitivity. Elevated GR activity should lead to more reduced glutathione which would generally be regarded as beneficial for redox homeostasis in chloroplasts (Mittler 2002). However, our finding matches that of Creissen et al. (1999) who increased GSH levels by transformation with a gene for a chloroplast-targeted $\gamma$-glutamylcysteine synthetase $(\gamma$-ECS) and found increased oxidative stress, which they explained on the basis of impaired redox sensing in the chloroplast. We contend that the increased MV sensitivity of the transplastomic lines over-expressing GR has a similar basis, although it is not reflected in a study in poplar (Foyer et al. 1995) in which chloroplast targeted GR did result in improved oxidative stress tolerance. Another study with tobacco (Broadbent et al. 1995) showed considerable interline variation, some GR over-expressing lines giving a modest increase in oxidative stress tolerance, while others did not. We found that elevation of plastid GR activity over-rides feedback control of glutathione synthesis leading to elevated total glutathione levels. Broadbent et al. (1995) and Foyer et al. (1995) report a similar finding in nuclear transformants of tobacco and poplar respectively.

One previously observed consequence of elevated chloroplast GR, namely tolerance to the heavy metal cadmium (Cd), was also found in the transplastomic GRoverexpressing plants. Cadmium is believed to result in lipid peroxidation (Gallego et al. 1996) as well as disrupting photosynthesis leading to ROS generation (Prasad 1995). Consequently, Pilon-Smits et al. (2000) demonstrated improved Cd tolerance in Brassica juncea plants with elevated GR targeted to the chloroplasts. In the present study a similar clear protective effect was found in germinating transplastomic tobacco seedlings expressing recombinant GR, but not MnSOD, in their chloroplasts. The marked difference between the responses to elevation of these two ROS scavenging enzymes may suggest that the primary role of elevated GR is not in ROS scavenging, but that it is due to the observed increase in the glutathione pool, glutathione being the precursor for the metal-binding peptides, phytochelatins (Cobbett 2000). However, the apparent lack of a protective effect in the MnSOD lines merits further investigation. Cd tolerance was the only stress explored at the seedling level in these lines and there could be major differences in the recombinant protein levels in the chloroplasts of mature leaves and seedlings. Various additional stress tests and analysis of antioxidant levels in these seedlings will be the subject of future studies.

UV irradiation is another stress for which ROS play a major role in mediating damage, and activities of several ROS scavenging enzymes, including both SOD and GR, are boosted by UV-B exposure (Jansen et al. 1998). The observed improvement in UV-B tolerance in response to over-expression of both enzymes in tobacco chloroplasts may again relate to improved ROS scavenging. However, there may be other factors in play. Phytochelatins (synthesised from glutathione) have been shown to have a role 
in UV-B tolerance in cyanobacteria (Bhargava et al. 2004), while $\mathrm{H}_{2} \mathrm{O}_{2}$ is an important oxidant in phenolpropanoid metabolism, and can therefore influence the synthesis of UV-screening compounds. Manipulation of cytosolic or apoplastic peroxidases has been shown to influence UVtolerance in tobacco (Jansen et al. 2004; Heggie et al. 2005), so diffusion into the cytosol of excess $\mathrm{H}_{2} \mathrm{O}_{2}$, a substrate of peroxidase, generated by MnSOD in the chloroplasts, might also affect the plant's response to UV. It should be emphasised that this UV protection would be due to alterations in phenolic metabolism in the absence of $\mathrm{UV}$, and is not due to induction of a defence response by UV-B, which would not be plausible during the short timeframe of high level exposure in these experiments.

This report demonstrates that the levels of enzymes associated with ROS scavenging can be modified through direct chloroplast transformation, and that the resulting enhancement of SOD or GR activity results in characteristic alterations in the response to several stresses. We believe that this direct tobacco chloroplast transformation approach has real attractions for further investigations into the roles of the various players in the complex process of oxidative stress amelioration in chloroplasts. The variable results obtained amongst independent nuclear transformants (e.g. Broadbent et al. 1995; McKersie et al. 1999) should be minimised by the targeted gene insertion, via homologous recombination, into the plastome (Svab et al. 1990), eliminating position effects and ensuring uniform expression levels. The lack of any known protein export mechanism from chloroplasts ensures the recombinant protein is localised to the target organelle, and obviates concerns over residual cytosolic expression due to inefficient chloroplast targeting. Furthermore, the importance of multi-component scavenging pathways, such as the ascorbate-glutathione cycle (Mittler 2002), together with the often limited effects of expressing individual components, suggest concerted expression of two or more genes might be more informative, something readily accomplished through chloroplast transformation (Bock 2001; Maliga 2004). This is illustrated by recent experiments in our laboratory (Le Martret et al. 2011) in which we combine expression of dehydroascorbate reductase (DHAR) and glutathione reductase (GR) in tobacco chloroplasts. These two enzymes constitute the parts of the ascorbate-glutathione cycle responsible for regenerating ascorbate, and the co-expressing plants exhibit a pronounced increase in tolerance to methyl viologen-mediated oxidative stress, whereas expression of the individual enzymes has a neutral (DHAR) or negative (GR) outcome. It is anticipated that further investigations of this kind will provide important insights into the interactions between the components of the stress defence armoury of this vulnerable organelle.
Acknowledgments This research was supported by grants from Science Foundation Ireland (grant: 06/RFP/EEB035) and Enterprise Ireland (grant: SC/2001/343). The authors would like to thank Manfred Klaas and Olga Grant for assistance in the preparation of the figures.

\section{References}

Allen RD (1995) Dissection of oxidative stress tolerance using transgenic plants. Plant Physiol 107:1049-1054

Aono M, Kubo A, Saji H, Tanaka K, Kondo N (1993) Enhanced tolerance to photooxidative stress of transgenic Nicotiana tabacum with high chloroplastic glutathione reductase activity. Plant Cell Physiol 34:129-135

Aono M, Saji H, Sakamoto H, Tanaka K, Kondo N, Tanaka K (1995) Paraquat tolerance of transgenic Nicotiana tabacum with enhanced activities of glutathione reductase and superoxide dismutase. Plant Cell Physiol 36:1687-1691

Arisi A-CM, Cornic G, Jouanin L, Foyer CH (1998) Overexpression of iron superoxide dismutase in transformed poplar modifies the regulation of photosynthesis at low $\mathrm{CO}_{2}$ partial pressures or following exposure to the prooxidant herbicide methyl viologen. Plant Physiol 117:565-574

Badawi GH, Kawano N, Yamauchi Y, Shimada E, Sasaki R, Kubo A, Tanaka K (2004a) Overexpression of ascorbate peroxidase in tobacco chloroplasts enhances the tolerance to salt stress and water deficit. Physiol Plant 121:231-238

Badawi GH, Yamauchi Y, Shimada E, Sasaki R, Kawano N, Tanaka K, Tanaka K (2004b) Enhanced toleranceto salt stress and water deficit by overexpressing superoxide dismutase in tobacco (Nicotiana tabacum) chloroplasts. Plant Sci 166:919-928

Bhargava P, Srivastava AK, Urmil S, Rai LC (2004) Phytochelatin plays a role in UV-B tolerance in $\mathrm{N}_{2}$-fixing cyanobacterium Anabaena doliolum. J Plant Physiol 162:1220-1225

Bhatnagar-Mathur P, Vadez V, Sharma KK (2008) Transgenic approaches for abiotic stress tolerance in plants: retrospect and prospects. Plant Cell Rep 27:411-424

Bock R (2001) Transgenic chloroplasts in basic research and plant biotechnology. J Mol Biol 312:425-438

Bowler C, Slooten L, Vanbranden S, De Rycke R, Botterman J, Sybesma C, Van Montagu M, Inzé D (1991) Manganese superoxide dismutase can reduce cellular damage mediated by oxygen radicals in transgenic plants. EMBO J 10:1723-1732

Bradford MM (1976) A rapid and sensitive method for quantification of microgram quantities of protein using the principal of proteindye binding. Anal Biochem 72:248-254

Broadbent P, Creissen GP, Kular B, Wellburn AR, Mullineaux PM (1995) Oxidative stress responses in transgenic tobacco containing altered levels of glutathione reductase activity. Plant $\mathrm{J}$ 8:247-255

Chen C-N, Pan S-M (1996) Assay of superoxide dismutase activity by combining electrophoresis and densitometry. Bot Bull Acad Sin 37:107-111

Cobbett CS (2000) Phytochelatins and their roles in heavy metal detoxification. Plant Physiol 123:825-832

Creissen G, Firmin J, Fryer M, Kular B, Leyland N, Reynolds H, Pastori G, Wellburn F, Baker N, Wellburn A, Mullineaux P (1999) Elevated glutathione biosynthetic capacity in the chloroplasts of transgenic tobacco plants paradoxically causes increased oxidative stress. Plant Cell 11:1277-1291

Daniell H (1997) Transformation and foreign gene expression in plants mediated by microprojectile bombardment. Methods Mol Biol 62:463-489 
Foster J, Hess J (1980) Responses of superoxide-dismutase and glutathione-reductase activities in cotton leaf tissue exposed to an atmosphere enriched in oxygen. Plant Physiol 66:482-487

Foyer CH, Descourvières P, Kunert KJ (1994) Protection against oxygen radicals: an important defence mechanism studied in transgenic plants. Plant Cell Environ 17:507-523

Foyer CH, Souriau N, Perret S, Lelandais M, Kunert KJ, Pruvost C, Jouanin L (1995) Overexpression of glutathione reductase but not glutathione synthase leads to increases in antioxidant capacity and resistance to photoinhibition in poplar trees. Plant Physiol 109:1047-1057

Gabriel O (1971) Analytical disc gel electrophoresis. Methods Enzymol 22:565-577

Gallego SM, Benavides MP, Tomaro ML (1996) Effect of heavy metal ion excess on sunflower leaves: evidence for involvement of oxidative stress. Plant Sci 121:151-159

Heggie L, Jansen MAK, Burbridge EM, Kavanagh TA, Thorneley RNF, Dix PJ (2005) Transgenic tobacco (Nicotiana tabacum L. cv. Samsun-NN) plants over-expressing a synthetic HRP-C gene are altered in growth, development and susceptibility to abiotic stress. Plant Physiol Biochem 43:1067-1073

Herrmann H, Häder D-P, Ghetti F (1997) Inhibition of photosynthesis by solar radiation in Dunaliella salina: relative efficiencies of UV-B, UV-A and PAR. Plant Cell Environ 20:359-365

Jansen MAK, Gaba V, Greenberg BM (1998) Higher plants and UV$\mathrm{B}$ radiation: balancing damage, repair and acclimation. Trends Plant Sci 3:131-135

Jansen MAK, Elfstrand M, Heggie L, Sitbon F, Dix PJ, Thorneley RNF (2004) Over-expression of phenol-oxidising peroxidases alters the UV-susceptibility of transgenic Nicotiana tabacum. New Phytol 163:585-594

Kim JS, Lee BH, Kwon SY, Kim YH, Kim SH, Cho KY (2005) Antioxidative responses of transgenic tobacco plants expressing both superoxide dismutase and ascorbate peroxidase in chloroplasts to several herbicides. Kor J Plant Biotechnol 32:97-103

Kimura M, Yoshizumi T, Manabe K, Yamamoto YY, Matsui M (2001) Arabidopsis transcriptional regulation by light stress via hydrogen peroxide-dependent and -independent pathways. Genes Cells 6:607-617

Kovtun Y, Chiu W-L, Tena G, Sheen J (2000) Functional analysis of oxidative stress-activated mitogen-activated protein kinase cascade in plants. Proc Natl Acad Sci USA 97:2940-2945

Kuroda H, Maliga P (2001) Sequences downstream of the translation initiation codon are important determinants of translation efficiency in chloroplasts. Plant Physiol 125:430-436

Kwon SY, Jeong YJ, Lee HS, Kim JS, Cho KY, Allen RD, Kwak SS (2002) Enhanced tolerances of transgenic tobacco plants expressing both superoxide dismutase and ascorbate peroxidase in chloroplasts against methyl viologen mediated oxidative stress. Plant Cell Environ 25:873-882

Le Martret B, Poage M, Shiel K, Nugent GD, Dix PJ (2011) Tobacco chloroplast transformants expressing genes encoding dehydroascorbate reductase, glutathione reductase, and glutathione-Stransferase, exhibit altered anti-oxidant metabolism and improved abiotic stress tolerance. Plant Biotechnol J (in press)

Lee SH, Ahsan N, Lee KW, Kim DH, Lee DG, Kwak SS, Kwon SY, Kim TH, Lee BH (2007a) Simultaneous overexpression of both $\mathrm{CuZn}$ superoxide dismutase and ascorbate peroxidase in transgenic tall fescue plants confers increased tolerance to a wide range of abiotic stresses. J Plant Physiol 164:1626-1638

Lee YP, Kim SH, Bang JW, Lee HS, Kwak SS, Kwon SY (2007b) Enhanced tolerance to oxidative stress in transgenic tobacco plants expressing three antioxidant enzymes in chloroplasts. Plant Cell Rep 26:591-598

Lidon FC, Teixeira MG (2000) Oxy radicals production and control in the chloroplast of Mn-treated rice. Plant Sci 152:7-15
Maliga P (2004) Plastid transformation in higher plants. Annu Rev Plant Biol 55:289-313

McCabe MM, Power JB, de Laat AMM, Davey MR (1997) Detection of single-copy genes in DNA from transgenic plants by nonradioactive Southern blot analysis. Mol Biotech 7:79-84

McKersie BD, Chen Y, De Beus M, Bowley SR, Bowler C, Inze D, D'Halluin K, Botterman J (1993) Superoxide dismutase enhances tolerance of freezing stress in transgenic alfalfa (Medicago sativa L). Plant Physiol 103:1155-1163

McKersie BD, Bowley SR, Jones KS (1999) Winter survival of transgenic alfalfa overexpressing superoxide dismutase. Plant Physiol 119:839-848

McKersie BD, Murnaghan J, Jones KS, Bowley SR (2000) Ironsuperoxide dismutase expression in transgenic alfalfa increases winter survival without a detectable increase in photosynthetic oxidative stress tolerance. Plant Physiol 122:1427-1437

Mittler R (2002) Oxidative stress, antioxidants and stress tolerance. Trends Plant Sci 7:405-410

Miyagawa Y, Tamoi M, Shigeoka S (2000) Evaluation of the defence system in chloroplasts to photooxidative stress caused by paraquat using transgenic tobacco plants expressing catalase from Escherichia coli. Plant Cell Physiol 41:311-320

Murashige T, Skoog F (1962) A revised medium for rapid growth and bioassays with tobacco tissue cultures. Physiol Plant 15:473-497

Nott A, Jung H-S, Koussevitzky S, Chory J (2006) Plastid-to-nucleus retrograde signalling. Ann Rev Plant Biol 57:739-759

Pfannschmidt T, Bräutigam K, Wagner R, Dietzel L, Schröter Y, Steiner S, Nykytenko A (2009) Potential regulation of gene expression in photosynthetic cells by redox and energy state: approaches towards a better understanding. Ann Bot 103:599-607

Pilon-Smits EAH, Zhu YL, Sears T, Terry N (2000) Overexpression of glutathione reductase in Brassica juncea: effects on cadmium accumulation and tolerance. Physiol Plant 110:455-460

Polidoros A, Scandalios JG (1999) Role of $\mathrm{H}_{2} \mathrm{O}_{2}$ and different classes of antioxidants in the regulation of catalase and glutathione S-transferase gene expression in maize. Physiol Plant 106:112120

Prasad MNV (1995) Cadmium toxicity and tolerance in vascular plants. Environ Exp Bot 35:525-545

Sambrook J, Fritsch E, Maniatis T (eds) (1989) Molecular cloning: a laboratory manual, 2nd edn. Cold Spring Harbor Laboratory, Cold Spring Harbor

Sen Gupta A, Heinen JL, Holaday AS, Burke JJ, Allen RD (1993) Increased resistance to oxidative stress in transgenic plants that overexpress chloroplastic $\mathrm{Cu} / \mathrm{Zn}$ superoxide dismutase. Proc Natl Acad Sci USA 90:1629-1633

Shi WM, Muramoto Y, Ueda A, Takabe T (2001) Cloning of peroxisomal ascorbate peroxidase gene from barley and enhanced thermotolerance by overexpressing in Arabidopsis thaliana. Gene 273:23-27

Slesak I, Karpinska B, Surówka E, Miszalski Z, Karpinski S (2003) Redox changes in the chloroplast and hydrogen peroxide are essential for regulation of $\mathrm{C}_{3}-\mathrm{CAM}$ transition and photooxidative stress responses in the facultative CAM plant Mesembryanthemum crystallinum L. Plant Cell Physiol 44:573-581

Slooten L, Capiau K, Van Camp W, Van Motagu M, Sybesma C, Inzé D (1995) Factors affecting the enhancement of oxidative stress tolerance in transgenic tobacco overexpressing manganese superoxide dismutase in the chloroplasts. Plant Physiol 107:737-750

Svab Z, Hajdukiewicz P, Maliga P (1990) Stable transformation of plastids in higher plants. Proc Natl Acad Sci USA 87:8526-8530

Tadić J, Juranić I, Moortgat GK (2001) Photooxidation of $n$-Hexanal in air. Molecules 6:287-299

Tanaka Y, Hibino T, Hayashi Y, Tanaka A, Kishitani S, Takabe T, Yokota S, Takabe T (1999) Salt tolerance of transgenic rice 
overexpressing yeast mitochondrial Mn-SOD in chloroplasts. Plant Sci 148:131-138

Tang L, Kwon SY, KimSH KimJS, Choi JS, Cho KY, Sung CK, Kwak SS, Lee HS (2006) Enhanced tolerance of transgenic potato plants expressing both superoxide dismutase and ascorbate peroxidase in chloroplasts against oxidative stress and high temperature. Plant Cell Rep 25:1380-1386

Tepperman J, Dunsmuir P (1990) Transformed plants with elevated levels of chloroplastic SOD are not more resistant to superoxide toxicity. Plant Mol Biol 14:501-511

Van Breusegem F, Slooten L, Stassart J-M, Botterman J, Moens T, Van Montagu M, Inzé D (1999) Effects of overproduction of tobacco MnSOD in maize chloroplasts on foliar tolerance to cold and oxidative stress. J Exp Bot 330:71-78

Van Camp W, Inzé D, Van Montagu M (1997) The regulation and function of tobacco superoxide dismutases. Free Radical Biol Med 23:515-520
Van Kooten O, Snel JFH (1990) The use of chlorophyll fluorescence nomenclature in plant stress physiology. Photosyn Res $25: 147-150$

Wang J, Zhang H, Allen RD (1999) Overexpression of an Arabidopsis peroxisomal ascorbate peroxidase gene in tobacco increases protection against oxidative stress. Plant Cell Physiol 40:725-732

Wang F-Z, Wang Q-B, Kwon S-Y, Kwak S-S, Su W-A (2005) Enhanced drought tolerance of transgenic rice plants expressing a pea manganese superoxide dismutase. J Plant Physiol 162:465472

Wang YC, Ou GZ, Li HY, Wu YJ, Wang C, Liu GF, Yang CP (2010) Enhanced salt tolerance of transgenic poplar plants expressing a manganese superoxide dismutase from Tamarix androssowii. Mol Biol Rep 37:1119-1124 